\title{
Species-wide homogeneity of nuclear ribosomal ITS2 sequences in the spider mite Tetranychus urticae contrasts with extensive mitochondrial COI polymorphism
}

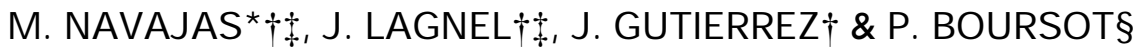 \\ †INRA-URLB, Laboratoire Modélisation et Biologie Evolutive, 488 rue Croix de Lavit, 34090 Montpellier, France, \\ †Institut des Sciences de I'Evolution (CNRS, UMR 5554), Laboratoire Génétique et Environnement, Université \\ Montpellier II, 34095 Montpellier, France and §Laboratoire Génome et Populations (CNRS, UPR 9060), Université \\ Montpellier II, 34095 Montpellier, France
}

\begin{abstract}
We compared patterns of intraspecific polymorphism of two markers with contrasted modes of evolution, nuclear ribosomal DNA (rDNA) and mitochondrial DNA (mtDNA), in the phytophagous mite Tetranychus urticae Koch. The second internal transcribed spacer (ITS2) of rDNA and a fragment in the mtDNA gene coding for Cytochrome Oxidase I (COI), were PCR-amplified and sequenced in samples of various geographical origins distributed worldwide. The 15 COI haplotypes found fell into two major phylogenetic lineages differing by an average of $5 \%$ nucleotide divergence. Samples from the Mediterranean basin were represented in both lineages, and showed no phylogeographical structure. The other samples, from temperate regions of the northern hemisphere, were clustered in one of the lineages and displayed little variation, indicating a recent colonization of this region. In contrast, no variation at all was found at the ITS2 in this species. We sequenced both COI and ITS2 in four other species of the genus Tetranychus and found that, despite the absence of intraspecific polymorphism, ITS appears to evolve 2.5 times faster than COI. We argue that rDNA homogeneity over the species range of T. urticae results from the high colonization potential of this species, preventing long-term differentiation. Preliminary data on two other mite species (Amphitetranychus viennensis Zacher and Mononychellus progresivus Doreste) with stricter ecological requirements and more restricted colonization potential revealed substantial and concordant geographical differentiation for both ITS2 and COI.
\end{abstract}

Keyw ords: cytochrome oxidase I (COI), internal transcribed spacer (ITS2), intraspecific variation, phylogeography, tetranychid mites.

\section{Introduction}

A major challenge in evolution is to infer evolutionary processes from the observation of patterns of variation. Because different regions of the genome can have different modes of evolution and/or transmission, they can be affected differently by evolutionary forces in natural populations, and thus convey complementary and/or contrasting information about the evolutionary history of the species. In fact, two of the most popular markers used in molecular evolution, mitochondrial DNA (mtDNA)

*Correspondence. E-mail: navajas@ensam.inra.fr and nuclear ribosomal DNA (rDNA), have quite different properties, which could translate into different consequences of mutation, drift, migration and selection on patterns of geographical variation and molecular divergence. The patterns of evolution of animal mtDNA and its performance as a marker of intraspecific variation are well understood (Avise, 1994; Simon et al., 1994). Nuclear ribosomal DNA has proven very useful in inferring species phylogenies at various evolutionary scales (Hillis \& Dixon, 1991). Despite rDNA being present in multiple copies in the genome, its use for that purpose is rendered possible because of the process of concerted evolution (Dover, 1982), ensuring intra- 
specific diversity to be generally reduced as compared to interspecific divergence. This property could apply to intraspecific variation, and geographical isolation between populations could lead to the fixation of alternative rDNA variants. Conversely, mixing of differentiated populations could lead to transient inter- and/or intraindividual heterogeneity. Studies of intraspecific polymorphism of the fast evolving internal transcribed spacers (ITS) have revealed different patterns of rDNA variation depending on the species. For instance, among arthropods, very low variation of the consensus sequences of individuals sampled over the whole species area was reported in Anopheline mosquitoes (Fritz et al., 1994). Low intraspecific variation has also been found in two tick species (McLain et al., 1995), in Drosophila (Schlötterer et al., 1994) and in strains of the Nasonia species complex (Campbell et al., 1993). However, substantial intraindividual heterogeneity of ITS sequences has been reported in two species of mosquitoes (Wesson et al., 1993), in blackflies (Tang et al., 1996) and in a beetle (Vogler \& DeSalle, 1994). It has been suggested that this extreme intraindividual variability, of the same order as interindividual variability, resulted from the fact that the species were subdivided into races, ecotypes or subspecies that had distinct histories, but between which a certain amount of secondary exchange occurred and fuelled the mixing of differentiated ITS sequences, delaying or preventing homogenization (Vogler \& DeSalle, 1994; Tang et al., 1996; Campbell et al., 1997). More studies of this type are needed, however, before any generalization can be made about the influence of geographical differentiation and gene flow on the degree of intraspecific homogeneity of rDNA.

One way to address the question of the influence of geographical isolation is to study in the same species both mtDNA and rDNA variation, using the former to infer historical patterns of gene flow. In this paper we study geographical variation of the mitochondrial cytochrome oxidase I gene (COI) and the second nuclear ribosomal internal transcribed spacer (ITS2) in the spider mite Tetranychus urticae Koch. This species is a cosmopolitan pest injurious to many crops. The mite is highly polyphagous, has been reported to occur on more than 900 different host plants and has been recorded in about 100 countries, with higher prevalence in areas with a temperate or Mediterranean climate. We present data showing the extent of ITS and mtDNA variation in this species. We also present preliminary data on the intraspecific variation of the two markers in two other mite species with greater specificity and ecological requirements. In order to interpret the differences observed between the patterns of intraspecific variation of the two markers, we also compared their rates of evolution between five different species of the same genus.

\section{Materials and methods}

Collection of mites

Specimens of T. urticae were collected from several host plants in 18 different localities from 12 different countries in the northern hemisphere between parallels 30 and 57 (Fig. 1 and Table 1). Samples include both green and red mites; these colours result from different haemolymph pigments (De Boer, 1985). Four other Tetranychus species (T. kanzawai Kishida, T. mcdanieli McGregor, T. pacificus McGregor and T. neocaledonicus André, Table 1) were analysed to assess the relative sequence divergence rate of the two markers studied. Several populations of two other tetranychid mites were also investigated (Table 1): two sites in Japan and four in France in the case of Amphitetranychus viennensis and two sites in South America and two in Africa for Mononychellus progresivus. Sequences of $M$. progresivus mites have been presented in a previous study (Navajas et al., 1994). In most cases animals caught in the field were analysed; in some cases we analysed their descendants born in the laboratory (Table 1).

\section{DNA extraction}

Total DNA was extracted from individual adult females. The material was either fresh, frozen or preserved in $100 \%$ ethanol. Ethanol-preserved specimens were rinsed for $10 \mathrm{~s}$ in $20 \mu \mathrm{L}$ of water three times prior to DNA extraction. The mite was crushed at $60^{\circ} \mathrm{C}$ with a plastic pestle in a $1.5 \mathrm{~mL}$ microcentrifuge tube containing $200 \mu \mathrm{L}$ extraction buffer (2\% CTAB, $1.4 \mathrm{M} \mathrm{NaCl}, 0.2 \%$ 2-b mercaptoethanol, 20 mм EDTA, $100 \mathrm{~mm}$ TRIS-HCl pH 8.0). The tube was incubated at $60^{\circ} \mathrm{C}$ for $5-30 \mathrm{~min}$. Proteins were removed with one volume chloroform/ isoamyl alcohol. DNA was precipitated with one volume isopropanol, the pellet was washed with ethanol $(76 \% \mathrm{v} / \mathrm{v}$ containing $10 \mathrm{~mm}$ of ammonium acetate) and resuspended in $20 \mu \mathrm{L}$ of double distilled water. Two or $4 \mu \mathrm{L}$ were used as a PCR template. For some samples (T. kanzawai, T. mcdanieli, T. pacificus, T. neocaledonicus and M. progresi$v u s)$, a rapid extraction protocol based on the chelating resin Chelex 100 was used as previously described in Navajas et al. (1996). 


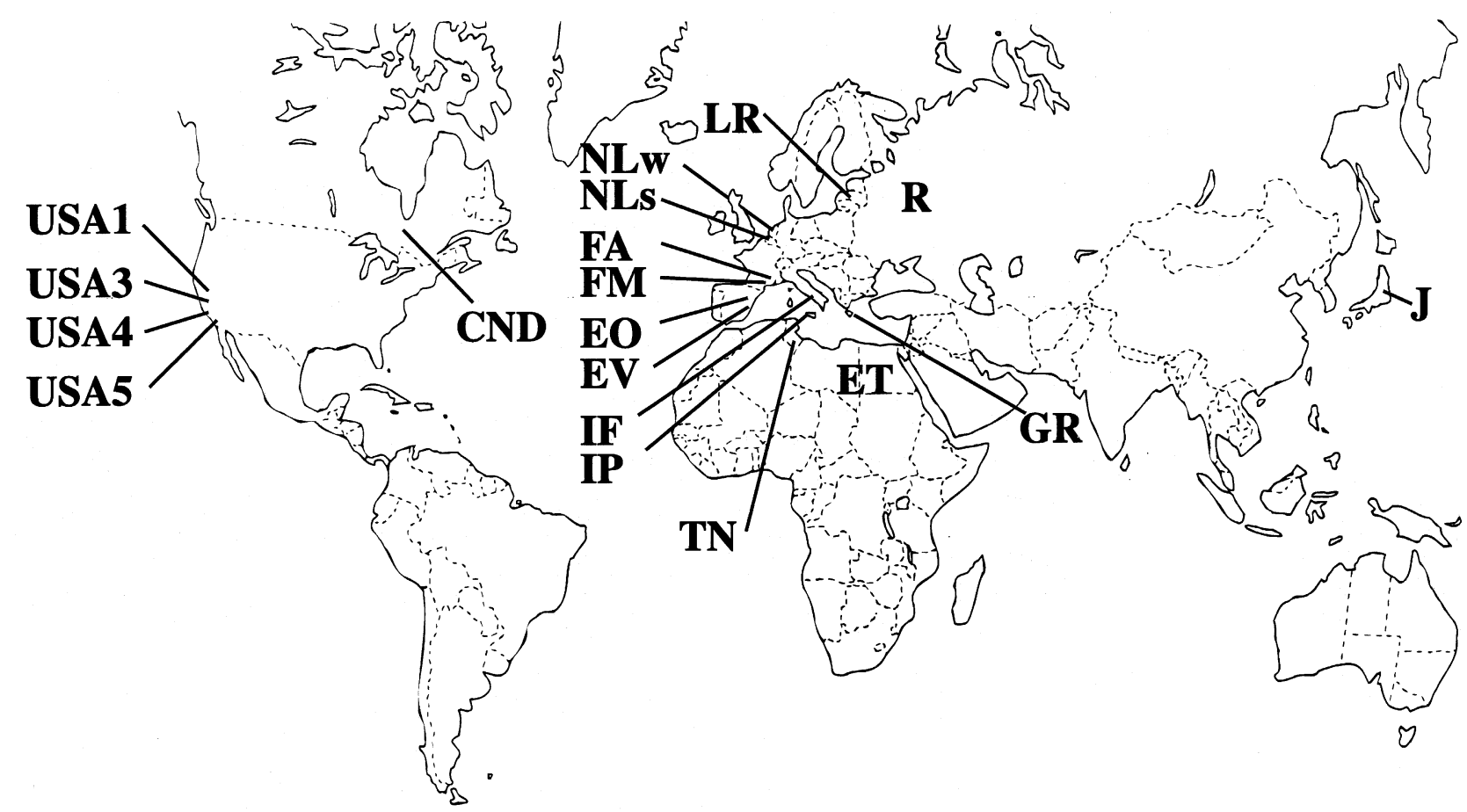

Fig. 1 Map of the sampling localities of the spider mite, Tetranychus urticae. The codes for each location are as in Table 1.

\section{PCR amplification and sequencing}

Two target DNA fragments were PCR-amplified and sequenced: the complete ribosomal ITS2 and a fragment in the central part of the mitochondrial $C O I$ gene. The amplification reactions were carried out in a $50 \mu \mathrm{L}$ volume containing 2 units of Taq polymerase (Eurogentec, Belgium), $1 \times$ enzyme buffer supplied by the manufacturer, 35 pmoles of each primer, 5 nmoles of each dNTP, 75 nmoles of $\mathrm{MgCl}_{2}$ and $2 \mu \mathrm{L}$ DNA as matrix in ITS2 amplification and $4 \mu \mathrm{L}$ DNA in COI amplification. After an initial denaturation step at $95^{\circ} \mathrm{C}$ for $4 \mathrm{~min}$, the reaction consisted of 35 cycles with $1 \mathrm{~min}$ at $92^{\circ} \mathrm{C}, 1 \mathrm{~min}$ at $51^{\circ} \mathrm{C}$ and $1.5 \mathrm{~min}$ at $72^{\circ} \mathrm{C}$. The PCR products were purified using glass beads (GeneClean II Kit, Bio 101, USA). One-third of the eluted volume was used for sequencing with a Sequenase 2.0 kit (US Biochemical Corp.) following the manufacturer's instructions and using ${ }^{35} \mathrm{SdATP}$ as label. We produced full sequences of both strands for one specimen from each origin of each species studied. Other specimens were sequenced for only one strand.

We used the COI primers previously designed specifically for tetranychid mites (Navajas et al., 1996). They were 5'-TGATTTTTTGGTCACCCAGAAG$3^{\prime}$ and 5'-TACAGCTCCTATAGATAAAAC-3'.
The ITS2 was amplified using the primers $5^{\prime}$-ATATGCTTAAATTCAGCGGG-3' and 5'-GGGTCGATGAAGAACGCAGC- $3^{\prime}$. These primers were defined in the highly conserved $5.8 \mathrm{~S}$ and $28 \mathrm{~S}$ flanking regions as previously published in Navajas et al. (1994) and subsequently modified to improve specificity for tetranychids. The same PCR primers were used for sequencing. Two additional primers were used for sequencing the ITS2 molecule: 5'-CGACTTTAGCGTCGTCAGAT-3' for all species and 5'-TATCTAGATCATGGGAAAT-3' for M. progresivus.

\section{Sequence analyses}

Phylogenetic analysis of the COI sequences was performed with several programs included in the PHYLIP 3.5c package (Felsenstein, 1993). Divergences between sequences were estimated using the program DNADIST, with the Kimura two parameter distance option (Kimura, 1980) and a transition/ transversion ratio of 2.0. A tree was built using the Neighbour Joining method (program NEIGHBOR). The same analyses were also performed on 1000 bootstrapped datasets generated by the program SEQBOOT. A majority rule consensus tree was determined from the resulting 1000 trees, using the program CONSENSE. The program MEGA 1.0 (Kumar 
Table 1 Collection sites of mites

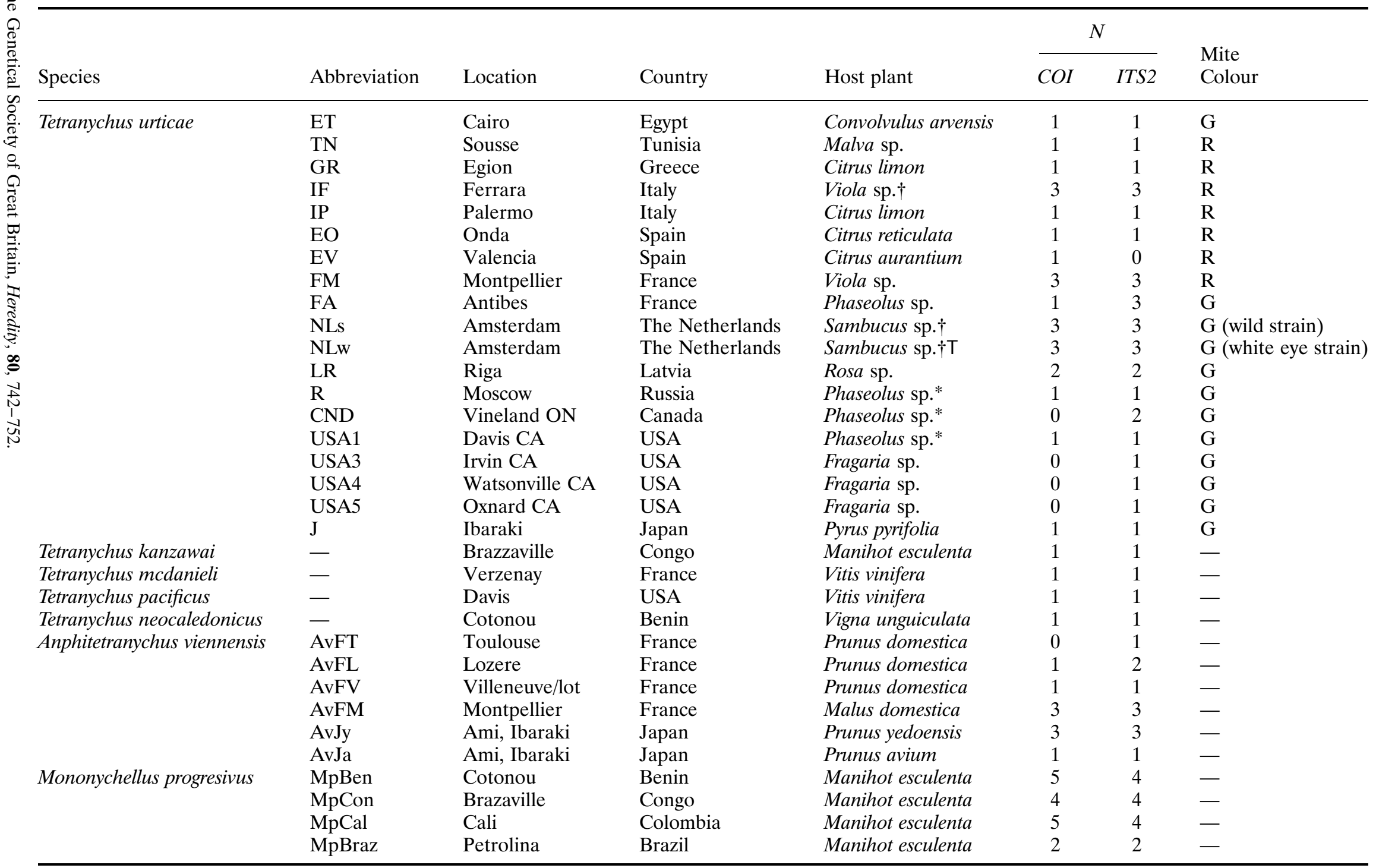

-, not applicable.

*The original host plant is unknown and the strain was reared on bean leaves.

$\dagger$ The host plant is indicated although the strain was reared for several generations on bean leaves.

Mite colour: G, Green; R, Red.

$\mathrm{N}$ indicates how many individuals have been analysed for each molecule. 
et al., 1993) was used to calculate distances between species of Tetranychus and their standard errors.

The sequences are deposited in the EMBL database under the following accession numbers: X77901, X80855-59, X80861 and X99873-5 for the COI sequences and X79902 and X99876-83 for the ITS2 sequences.

\section{Results}

\section{Interspecific ribosomal ITS2 sequence variation}

The complete ITS2 and portions of the flanking 3' end of the $5.8 \mathrm{~S}$ and the $5^{\prime}$ end of the $28 \mathrm{~S}$ were PCR-amplified and sequenced in five species of the genus Tetranychus, as well as in $A$. viennensis and $M$. progresivus. The boundaries of ITS2 were determined using the conserved sequence of the two flanking regions (5.8S and 28S). Alignments of sequences among Tetranychus species implied only very short insertions/deletions and did not pose any problem. Alignment between the different genera was attempted using secondary structure inference (not shown) and is presented in Fig. 2. Its quality is irrelevant because we did not use any intergeneric comparisons in the present study.

The length of the ITS 2 sequence was $\cong 480$ base pairs (bp) in the Tetranychus species examined, and was shorter in A. viennensis (445 bp) and longer in M. progresivus ( $805 \mathrm{bp}$ ). One insertion of $283 \mathrm{bp}$ located at position 201 in the sequence of $M$. progresivus accounts for much of its additional length. This is the longest ITS2 recorded for arthropods. The length of the ITS2 of the other tetranychids examined here falls within the range of the known size of ITS2 in arthropods: $\cong 280$ in the aphid Acyrthosiphon pisum (Kwon \& Ishikawa, 1992); $\cong 430$ in the wasp Nasonia (Campbell et al., 1993); $\cong 353-408$ in Drosophila species (Schlötterer et al., 1994), from $\cong 360 \mathrm{bp}$ (Fritz et al., 1994) to $\cong 430 \mathrm{bp}$ (Porter \& Collins, 1991) in Anopheles mosquitoes and 678-728 bp in Ixodes species (Wesson et al., 1993).

The $\mathrm{G}+\mathrm{C}$ contents in the ITS2 sequences do not vary significantly between tetranychid species $\left(\chi^{2}\right.$ nonsignificant) and range from $31.2 \%$ for $T$. urticae to $39 \%$ for $M$. progresivus. These constitute intermediate values of $\mathrm{G}+\mathrm{C}$ content with respect to other arthropods sequenced: $20-21.5 \%$ in Drosophila (Schlötterer et al., 1994); 55.3-59\% in culicid mosquitoes (Wesson et al., 1992; Fritz et al., 1994) and 46.7-47.2\% in ticks (McLain et al., 1995). The percentage of $\mathrm{G}+\mathrm{C}$ is higher in the sequenced $5.8 \mathrm{~S}$ fragment of tetranychid species $(50.5-53.8 \%)$, than in the ITS2 sequences $\left(\chi_{6}^{2}=42, P<0.01\right)$.
We calculated the pairwise nucleotide divergence among five Tetranychus mite species and the distance matrix appears in Table 2a. In pairwise comparisons, we have excluded positions with a gap in one of the two sequences. Nucleotide divergences ranged from $1.3 \%$ between $T$. urticae and $T$. kanzawai, to 14.1-16.1\% between T. neocaledonicus and all the other species.

\section{Interspecific COI vs. ITS2 divergence}

Table $2 \mathrm{~b}$ shows the $C O I$ pairwise nucleotide divergences of the five Tetranychus species studied, based on the $390 \mathrm{bp}$ fragment sequenced (data from Navajas et al., 1996). Divergence is $6.2 \%$ between $T$. urticae and T. kanzawai, and ranges from 10.2 to $11.6 \%$ between $T$. neocaledonicus and the other species.

Figure 3 allows the comparison of the ITS2 and COI divergences between pairs of Tetranychus species. It can be seen that $C O I$ divergence is higher than that of ITS2 at low divergences, comparable at intermediate divergences (around 8\%), and lower at higher divergences (around 15\% ITS divergence). The slope of the regression between ITS2 and COI divergence indicates that ITS2 evolves about 2.5 times faster than $C O I$. Note that the intercept of the regression of $C O I$ against ITS2 crosses the $C O I$ axis at 5\% divergence, meaning that zero ITS2 divergence corresponds to an expected $C O I$ divergence of $\approx 5 \%$ (see Discussion).

\section{Intraspecific variation of ITS2 sequences}

The complete ITS2 sequence of 30 individuals of $T$. urticae from 18 localities described in Fig. 1 and Table 1 was determined. Intrapopulation variation was investigated by sequencing two to three individuals in seven of the sampled localities (IF, FM, FA, NLs, NLw, LR and CDN; Table 1). All 30 individuals examined for $T$. urticae had the ITS2 sequence shown in Fig. 2.

The lack of intraspecific variation of the ITS2 sequences in $T$. urticae contrasts with the results obtained for the two other mite species, although the latter were sampled much less intensively. Among the four different geographical origins of $M$. progresivus, the Brazilian individuals were different (by two transversions) from those of all other origins: Colombia, Congo and Benin. There were 10 differences (two transversions, seven transitions and one $3 \mathrm{bp}$ insertion/deletion) between the ITS2 sequences of $A$. viennensis strains from France and

(C) The Genetical Society of Great Britain, Heredity, 80, 742-752. 


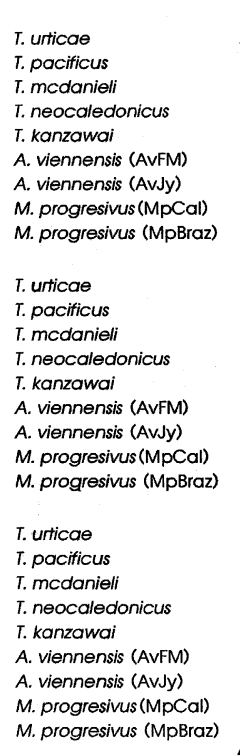

T. urticae

T. pacificus

T. mcdaniel

T. neocaledonicus

T. kanzawai

A. viennensis (AVFM)

A. viennensis (AvJy)

M. progresivus (MpCal)

M. progresivus (MpBraz)

T. unticae

T. pacificus

T. mcdanieli

T. neocaledonicus

T. kanzawai

A. viennensis (AvFM)

A. viennensis (AvJy)

M. progresivus (MpCal)

M. progresivus (MpBraz)

T. unticae

T. pacificus

I. medanieli

T. neocaledonicus

T. kanzawai

A. viennensis (AvFM)

A. viennensis (AvJy)

M. progresivus (MpCal)

M. progresivus (MpBraz)

T. urticae

T. pacificus

T. mcdanieli

T. neocaledonicus

T. kanzawai

A. viennensis (AvFM)

A. viennensis (AvJy)

M. progresivus (MpCal)

M. progresivus (MpBraz)

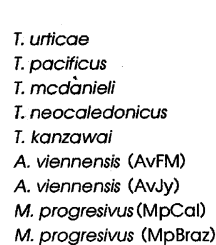

$5.8 \mathrm{~S} \longrightarrow$

AAGAACGCAGCTAGCTACGATAATCTGGTGCGATTGCAGGACACGCCGAGCACTTGAGCTTCCAACGCACATTGCGGCTTCGGGTCTTTCCGAGTC -1
-

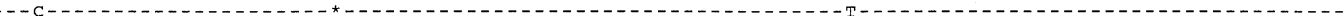

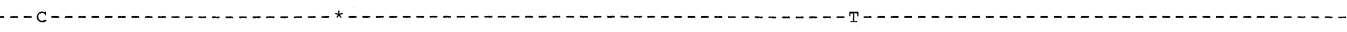
NNNNN NNNNN-1-10

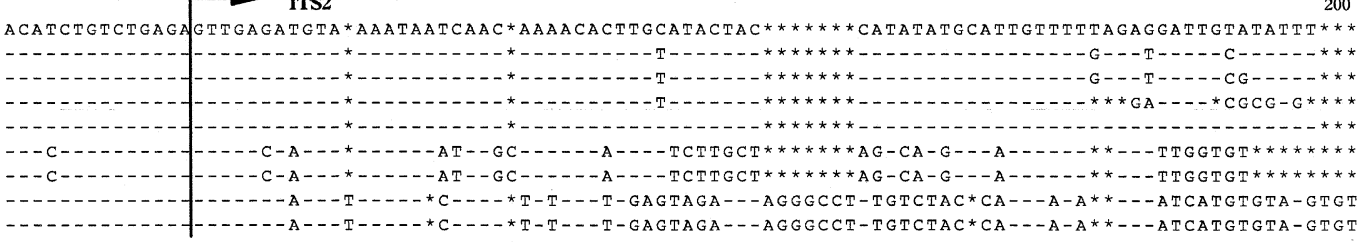
*********ATATGCATGAATCTTGATGTTTTATTCCTTTTCTT*AATGCAATT $* * * * * * * * * * * *$ CGTTGCAATTAGTAAGAGATCTCAAATCT

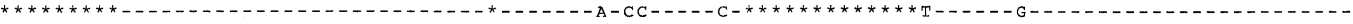
*********

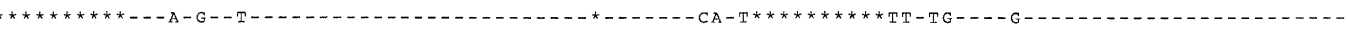
********* $* * * * * * * * * * * * *$ AATGCT A-

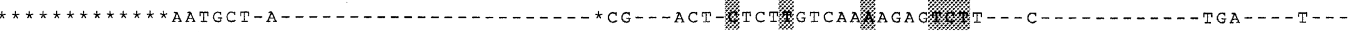
GCACACATTTCCCAT*GAT**--A---A--C---

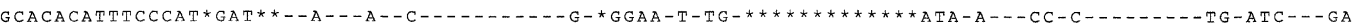
283 pbinsert

ACTTGTTTCACATGATA*AATTTGTGTACAATGCATATTTC**ATCTCT**GCAAG*CAGTATA*TATGAATAGATACTAGCATGAGATTCTAAGTT A C. -

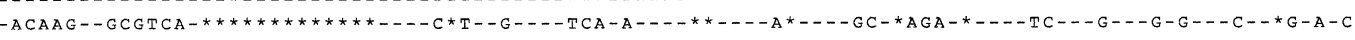

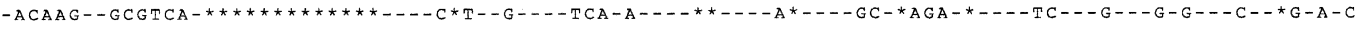
TG-GA-A--TTGAT--*CTG-A-GC-ACTAC-GCT-GTAAG-GGC-GAG-AGCAGTT-ATCTG-CTG-CAAGCA-ATC---G---*-G--CC--G--AGA TG-GA-A--TTGAT- - $C T$ T -A-GC-ACTAC-GCT-GTAAG-GGC-GAG-AGCAGTT-ATCTG-CTG-CAAGCA-ATC---G---*-G--CC--G--AGA

AGTCGCCTATCTGACGACGCTAAATCGTATTGCAGATAACTATGGTGATCAA**************CTAACCTGTTAACTGATGA*ATCTTC*TTGCA (1) G G- CC- T-A-- C-1 -

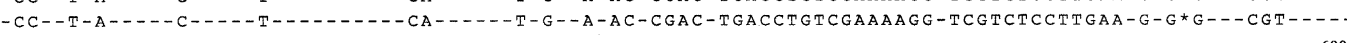

CTTGTATAAA******* TCGTACAAATAGTAGCTATTTC**AT*TCTGTT*AAAGCAGACCTAAG**AAG*TAATGCAAAGGC*AAAATTGTGCAAAC C -

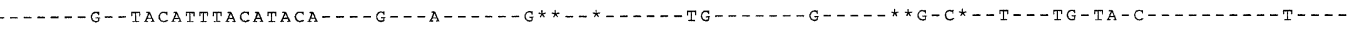

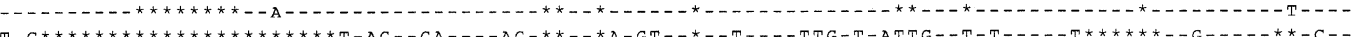

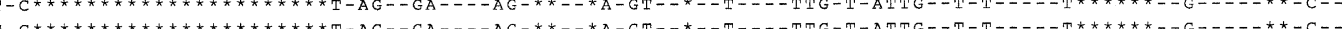

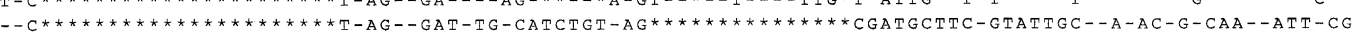

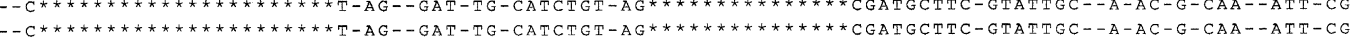

700

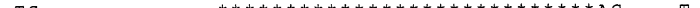
GATITACGTIGCT GAT- G- - - - -

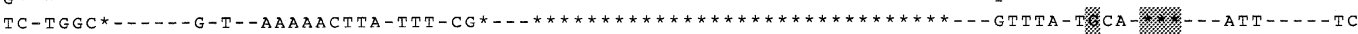

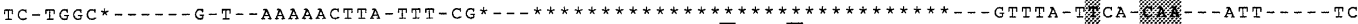

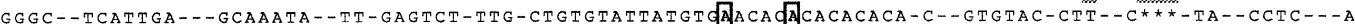
GGGC--TCATTGA---GCAAATA--TT-GAGTCT-TTG-CTGTGTATTATGT IdACA dICACACACA-C--GTGTAC-CTT--C***-TA--CCTC--- A

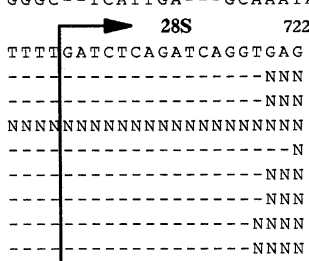

Fig. 2 Partial 5.8S and complete ITS2 sequences (5' to $\left.3^{\prime}\right)$ of Tetranychus urticae and six other tetranychid mite species. Identities with the T. urticae sequence are indicated by dashes, and asterisks represent gaps. A 283 bp insertion in position 201 was detected in the Mononychellus progresivus sequence. Intraspecific comparisons are provided for strains of Amphitetranychus viennensis and Mononychellus progresivus and polymorphic sites are highlighted.

(C) The Genetical Society of Great Britain, Heredity, 80, 742-752. 
Table 2 Pairwise nucleotide distance (upper-right matrix) and standard errors (lower-left matrix) among five tetranychid mite species. The Tamura (1992) correction for multiple substitutions was used based on: (a) ribosomal ITS2 sequences and (b) mitochondrial COI sequences. Positions with a gap in one of the sequences were excluded

T. urticae T. kanzawai T. mcdanieli T. pacificus T. neocaledonicus

\begin{tabular}{llllll}
\hline (a) & & & & & \\
Tetranychus urticae & & 0.013 & 0.077 & 0.089 & 0.149 \\
T. kanzawai & 0.005 & & 0.072 & 0.084 & 0.141 \\
T. mcdanieli & 0.013 & 0.013 & & 0.015 & 0.148 \\
T. pacificus & 0.014 & 0.014 & 0.007 & & 0.161 \\
T. neocaledonicus & 0.020 & 0.019 & 0.019 & 0.020 & \\
(b) & & & & & \\
Tetranychus urticae & & 0.062 & 0.075 & 0.088 & 0.115 \\
T. kanzawai & 0.014 & & 0.075 & 0.078 & 0.102 \\
T. mcdanieli & 0.016 & 0.016 & & 0.055 & 0.108 \\
T. pacificus & 0.017 & 0.016 & 0.013 & & 0.116 \\
T. neocaledonicus & 0.020 & 0.018 & 0.019 & 0.020 & \\
\hline
\end{tabular}

Japan (Fig. 2). Four different localities were sampled in France and two in Japan and all the mites in each country had identical ITS2 sequences.

\section{Mitochondrial COI intraspecific variation}

The sequence of a COI fragment (390 bp) was determined in $24 \mathrm{~T}$. urticae individuals also analysed for ITS2 (Table 1). Comparisons of T. urticae sequences revealed 26 variable positions, all of which involved only point mutations (Fig. 4). The analysis of variable sites shows that the COI sequences cluster in two major groups referred to as lineages I and II. Nine of the variable sites are diagnostic between these two lineages. Lineage I contains either red or green forms of mites originating only from the Mediterranean area and collected from Phaseolus sp. (FA), Malva sp. (TN) and Citrus spp. (GR, EO, EV). Lineage II, in addition to other Mediterranean origins (FM, IF, IP and ET) includes all other samples originating from four different continents. The phylogenetic tree inferred from the COI sequences is shown in Fig. 5. High bootstrap scores give confidence to support the existence of two major lineages. The nucleotide divergence between these lineages is about $5.0 \%$ on average. Branching orders inside each lineage are not well resolved by this short sequence and will not be discussed.
Fig. 3 Plot of $C O I$ vs. ITS2 divergences in pairwise comparisons of five Tetranychus species (Table 2). Standard errors around the data points are indicated. The dotted line is the diagonal $(C O I=$ ITS $)$. The thick line is the linear regression, the equation of which is shown on the graph.

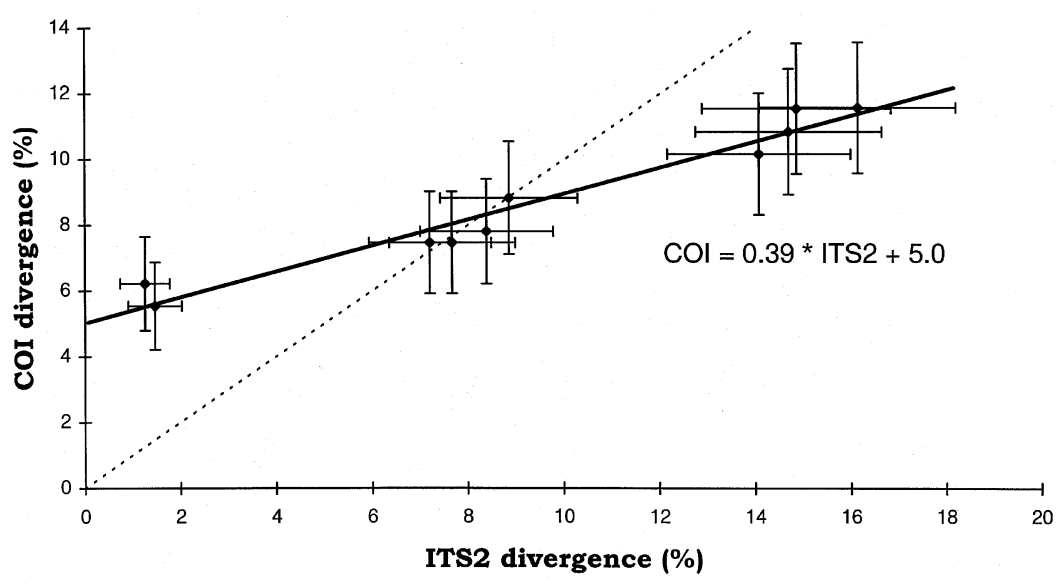

(C) The Genetical Society of Great Britain, Heredity, 80, 742-752. 


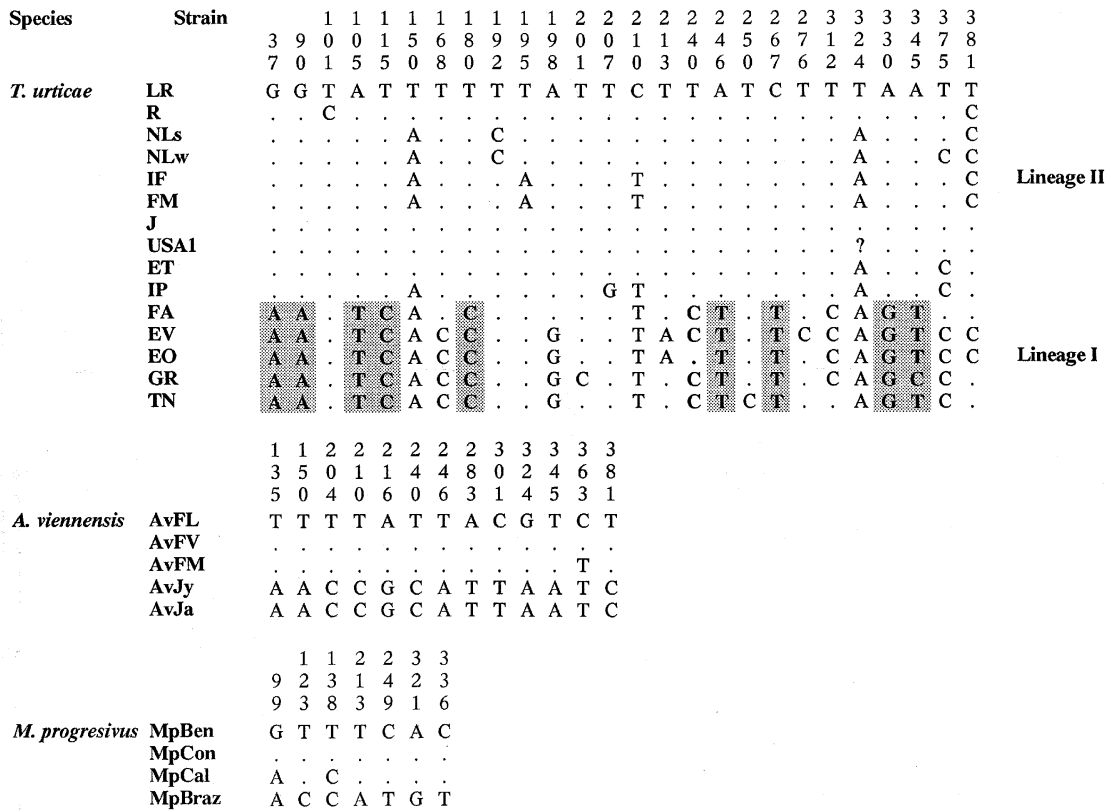

Fig. 4 Variable nucleotide sites among $C O I$ sequences of samples of three tetranychid species. Abbreviations of collection sites are as in Table 1 . The base numbers refer to the position in the published nucleotide sequence of Tetranychus urticae (Navajas et al., 1996). Dots indicate identity with the first sequence for each species. The nucleotide substitutions that are diagnostic between the two lineages of $T$. urticae are highlighted.

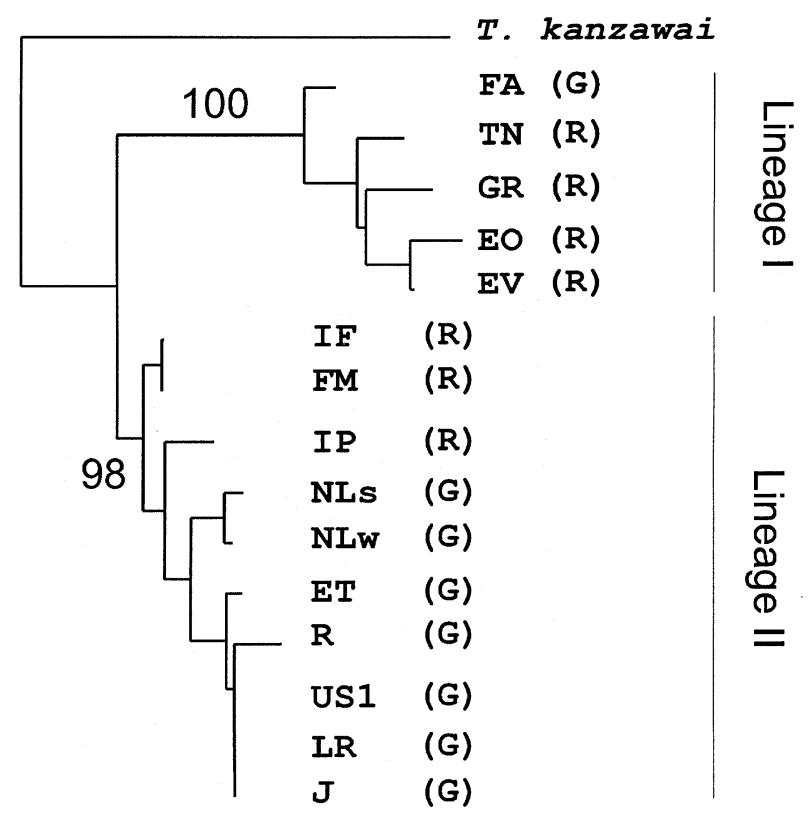

Fig. 5 Phylogenetic tree inferred from COI nucleotide sequences of various samples of Tetranychus urticae. The Neighbour Joining method was used based on distances calculated using Kimura's two-parameter correction method. The codes for each location are as in Table 1. The species Tetranychus kanzawai was used as outgroup. Bootstrap scores are indicated for the two major lineages. Mite colouration for each sample is indicated in brackets: $(\mathrm{R})=$ red; $(\mathrm{G})=$ green .

(C) The Genetical Society of Great Britain, Heredity, 80, 742-752.
Intraspecific variation of $C O I$ sequences was also recorded in the two other tetranychid mites considered in this study, $A$. viennensis and $M$. progresivus (Fig. 4). Intraspecific differences in COI sequences in these two species are congruent with ITS2 variation and correlate with the geographical origin of mite samples: 12-13 single nucleotide changes clearly differentiate the two French haplotypes of $A$. viennensis from the Japanese one (3.6-3.9\% divergence). The $M$. progresivus mites from Brazil differ from all other origins by five to seven substitutions (1.5-2.1\% divergence). Two sites are diagnostic between the American and the African samples. There were no intrasample differences in any of the species investigated.

\section{Discussion}

Our study shows complete homogeneity of ITS2 consensus sequences in different populations of $T$. urticae collected from several host plants in an extensive geographical area. In contrast, we found for the same mites substantial divergence in the $C O I$ sequences (around 5\% between two major lineages that were detected). This contrast does not appear to be linked to a slower evolution rate of ITS2. In fact, the comparison of interspecific divergences of ITS2 and COI in Fig. 3 rather suggests that ITS2 evolves about 2.5 times faster than $C O I$ in the genus Tetranychus. The fact that the regression of COI against ITS2 divergences does not go through the 
origin means that $C O I$ divergence predates species divergence to a greater extent than does ITS divergence. In fact, a retention of ancestral polymorphism may cause molecular divergence to be substantially older than species divergence as was for instance reported in two extreme examples involving closely related species of mice (Fort et al., 1984) and hares (Pérez-Suarez et al., 1994). Our results on mites could mean that ancestral polymorphism is generally higher for COI than for ITS2, but this is not the only possible explanation. As a result of the method used (direct sequencing of PCR products amplified from genomic DNA) we determined the consensus ITS sequences of the different species. This sequence is likely to be identical to, or close to, the ancestor of the sequences of the different copies of ITS2 in the genome of the species, and we are thus blind to intraspecific polymorphism between copies of the sequence. On the other hand, the polymorphism that was present in the ancestral species is not hidden, because it becomes observable once the descendants of alternative copies have been fixed in the genomes of the sister species. Thus species divergence times based on ITS consensus sequence divergence should be biased downwards as result of overlooking intraspecific polymorphism, but upwards because polymorphism of the ancestral species is incorporated in this divergence. Overall, ITS consensus sequence divergence should thus provide a more or less accurate estimate of species divergence time, provided levels of intraspecific polymorphism do not vary too much over time and between lineages. That the regression of $C O I$ against ITS2 divergence does not go through the origin (Fig. 3) is not necessarily accounted for by ancestral polymorphism being higher for mtDNA, but could also be explained by the fact that ancestral polymorphism is indirectly corrected for when measuring interspecific ITS consensus sequence divergences (note that these explanations are not exclusive). This would mean that ancestral polymorphism for $C O I$ is of the order of 5\% (see the intercept of the regression in Fig. 3). This appears a plausible value, because we found an average of $5 \%$ divergence between the two major COI lineages in T. urticae, and $3.9 \%$ between haplotypes sampled in $A$. viennensis.

The reasoning above applies whatever the amount by which individual copies of ITS vary from the consensus sequence of the species. This amount depends on the efficiency of the concerted evolution process, which presumably results from a variety of mechanisms of nonreciprocal DNA transfer, including gene conversion (Nagylaki, 1984), unequal crossing-over (Smith, 1976; Dover, 1982), and intrachromosomal exchanges (Schlötterer et al., 1994). The efficiency of the concerted evolution process in $T$. urticae cannot be assessed from our data because we did not determine the sequence of individual repeats of the ITS2. However, the invariance of the ITS2 consensus sequence over the species range would seem to indicate a certain homogeneity of the rDNA pool of this species.

Our mtDNA polymorphism data in $T$. urticae allow us to judge the homogeneity of this species. It has long been considered as a complex of species because of differences in morphology, haemolymph pigments and response to photoperiod, and of results of cross-breeding experiments (Bund \& Helle, 1960; Parr \& Hussey, 1960; Boudreaux, 1963; Veerman, 1970, 1974). Partial incompatibilities between closely adjacent populations were found in agricultural as well as in natural environments (Helle \& Pieterse, 1965; De Boer, 1985), and might be related to the presence of Wolbachia (Tsagkarakou et al., 1996), an endosymbiont which is involved in cytoplasmic incompatibilities (Barr, 1982) and may be associated with genetic and phenotypic variation. Studies of nuclear gene polymorphisms at a restricted geographical scale have revealed patterns of isolation by distance and sometimes by host plant (Tsagkarakou et al., 1997, 1998). The analysis of mtDNA variation reveals the existence of very divergent lineages, but no correlation between mtDNA divergence and either host plant or physiological characteristics, such as red (T. urticae cinnabarinus) or green haemolymph (T. urticae sensu stricto) (Table 1 and Fig. 5).

However, on the geographical scale sampled in this study and given the time spanned by the observed COI variation, the present mtDNA data reflect the colonization history of the species rather than local and labile differentiation. The Mediterranean region possesses the highest phyletic mtDNA diversity; in addition, one of the two lineages detected (lineage I) consists entirely of Mediterranean samples (Figs 4 and 5). Seen together, these two points appear to indicate substantial age of colonization in the region. It is noteworthy that a very little diversified clade includes most of the non-Mediterranean origins sampled: R (Russia), US1 (USA), LR (Latvia) and J (Japan), suggesting that non-Mediterranean regions of the northern hemisphere were recently colonized by a subset of the Mediterranean population. Inside the Mediterranean region, there is no apparent phylogeographical structure in the data, and thus no evidence of long-standing genetic isolation between geographical regions. This and the evidence for recent coloniza- 
tion of the northern temperate regions fits well with the absence of rDNA differentiation. Furthermore, the fact that substantial mtDNA polymorphism and divergence (up to $5 \%$ between the major lineages) is found in this species indicates that a bottleneck is unlikely to be responsible for the homogenization of ITS sequences over the whole species range.

Species-wide homogenization of rDNA sequences does not appear to be a constant in mites; a certain variability in ITS2 sequences was detected in the two other mite species analysed for this purpose. In $A$. viennensis, we found $2.0 \%$ ITS2 divergence between the French and Japanese samples, which differed by $3.6-3.9 \%$ for COI. The divergences are more reduced in $M$. progresivus, which showed about $2 \%$ COI divergence, but only $0.25 \%$ ITS 2 divergence, between the Brazilian samples and the others. In both cases however, different ITS2 sequences were only found between samples that also had the most divergent $C O I$ sequences, indicating a concordance of the information of the two markers, and suggesting the absence of gene flow between regions with different ITS2 sequences.

The results reported here may be related to ecological factors, with the feeding and ecological specificity of the mite species providing a key factor conditioning the opportunities of long-distance migration and colonization. In contrast to the highly polyphagous $T$. urticae, $M$. progresivus is a monophagous tetranychid that feeds only on cassava plants, and $A$. viennensis is oligophagous and feeds only on Rosaceae. Furthermore, the colonization abilities of these last two species appear to be limited by factors other than host plant availability. The American species $M$. progresivus follows the distribution of the host plant, Manihot esculenta, in Central and South America. However, the mite has established only in Africa, in spite of the presence of cultivated cassava in other continents (south-east Asia, USA). Similarly, the distribution of $A$. viennensis is restricted to Eurasia, despite the recurrent introductions of cultivated Rosaceae worldwide.

A better knowledge of the mechanisms and kinetics of concerted evolution of rDNA is clearly needed before the relative performances of rDNA and mtDNA in detecting historical barriers to gene flow can be fully assessed. It is not known whether the homogenization of rDNA sequences in an isolated population takes more or less time than the sorting of mtDNA lineages leading to the monophyly of the population for this marker. In any case, the conjunction of information on different markers is preferable to the reliance on the particular history of a single gene.

(C) The Genetical Society of Great Britain, Heredity, 80, 742-752.

\section{Acknow ledgements}

We are grateful to C. Schlötterer for helpful comments on the manuscript. We thank B. Michot for performing secondary structure analysis of ITS2 sequences. We also thank the following for kindly providing mite specimens: $\mathrm{H}$. Bolland, University of Amsterdam, The Netherlands; O. Bonato, ORSTOM, Montpellier, France; G. Fédière, ORSTOM, Cairo, Egypt; F. Garcia-Mari, Universidad Politecnica Valencia, Spain; G. Fauvel, INRA, Montpellier, France; T. Gotoh, Ibaraki University, Japan; R. Karban, UCDavis, USA; S. Kreiter, ENSAM, Montpellier, France; A. Tsagkarakou, Benaki Institute, Greece; H. Thistlewood, AgriCanada, Vineland, Canada; and D. Walsh, UCDavis, USA. This is contribution ISEM96 104.

\section{References}

AVISE, J. C. 1994. Molecular Markers, Natural History and Evolution. Chapman and Hall, New York.

BARR, A. R. 1982. Symbiont control. of reproduction in Culex pipiens. In: Steiner, W. J., Tabachnick, W. W. M., Rai, K. S. \& Narang, S. (eds) Recent Developments in the Genetics of Insect Disease Vectors, pp. 153-158. Stipes Publishing, Champaign, IL.

BOUdREAUX, H. B. 1963. Biological aspects of some phytophagous mites. Ann. Rev. Entomol., 8, 137-154.

BUND, C. F. AND HELLE, w. 1960. Investigations on the Tetranychus urticae complex in North West Europe. Entomologia exp. appl., 3, 142-156.

CAMPBELL, B. C., STEFFEN-CAMPBELL, J. D. AND WERREN, J. H. 1993. Phylogeny of the Nasonia species complex (Hymenoptera: Pteromalidae) inferred from an internal transcribed spacer (ITS2) and 28S rDNA sequences. Insect Mol. Biol., 2, 225-237.

CAMPBEll, C. S., WOJCIECHOWSKI, M. F., BALDWIN, B. C., Alice, L. A. AND DONOGHUe, M. J. 1997. Persistent nuclear ribosomal DNA sequence polymorphism in the Amelanchier agamic complex (Rosaceae). Mol. Biol. Evol., 14, 81-91.

DE BOER, R. 1985. Reproductive barriers. In: Helle, W. \& Sabelis, M.S. (eds) World Crop Pests. Spider Mites: Their Biology, Natural Enemies and Control., Vol. IA, pp. 193-200. Elsevier, Amsterdam.

DOVER, G. 1982. Molecular drive: a cohesive mode of species evolution. Nature, 299, 111-117.

FELSENSTEIN, J. 1993. PHYLIP (Phylogeny Inference Package), Version 3.5p edn. Department of Genetics, University of Washington, Seattle.

FORT, P., BONHOMME, F., DARLU, P., PIECHACZIK, M., JEANTEUR, P. AND THALER, L. 1984. Clonal divergence of mitochondrial DNA vs. populational evolution of nuclear genome. Evol. Theory, 7, 81-90.

FRITZ, G. N., CONN, J., COCKBURN, A. AND SEAWRIGHT, J. 1994. Sequence analysis of the ribosomal DNA internal transcribed spacer 2 from a population of Anopheles 
nuneztovari (Diptera: Culicidae). Mol. Biol. Evol., 11, 406-416.

Helle, W. AND PIETERSE, A. H. 1965. Genetic affinities between adjacent populations of spider mites. Entomologia exp. appl., 8, 305-308.

HILLIS, D. M. AND DIXON, M. T. 1991. Ribosomal DNA: molecular evolution and phylogenetic inference. $Q$. Rev. Biol., 66, 411-453.

KIMURA, M. 1980. A simple model for estimating evolutionary rates of base substitutions through comparative studies of nucleotide sequences. J. Mol. Evol., 16, 111-120.

KUMAR, S., TAMORA, K. AND NEI, M. 1993. MEGA: Molecular Evolutionary Genetics Analysis, 1.0 edn. Pennsylvania State University, University Park, PA.

KWON, O. AND ISHIKAWA, H. 1992. Nucleotide sequence and presumed secondary structure of the internal transcribed spacers of rDNA of the pea aphid, Acyrthosiphon pisum. Comp. Biochem. Physiol., 103B, 651-655.

MCLAIN, D. K., WESSON, D. M., COLLINS, F. H. AND OLIVER, J. H., JR. 1995. Evolution of the rDNA spacer, ITS2, in the ticks Ixodes scapularis and I. pacificus (Acari: Ixodidae). Heredity, 75, 303-319.

NAGYLAKI, T. 1984. Evolution of multigene families under interchromosomal gene conversion. Proc. Natl. Acad. Sci. U.S.A., 81, 3796-3800.

NAVAJAS, M., GUTIERREZ, J., BONATO, O., BOLlaND, H. R. AND MAPANGOU-DIVASSA, s. 1994. Intraspecific diversity of the cassava green mite Mononychellus progresivus (Acari: Tetranychidae) using comparisons of mitochondrial and nuclear ribosomal DNA sequences and crossbreeding. Exp. Appl. Acarol., 18, 351-360.

NAVAJAS, M., GUTIERREZ, M., LAGNEL, J. AND BOURSOT, P. 1996. Mitochondrial cytochrome oxidase I in tetranychid mites: a comparison between molecular phylogeny and changes of morphological and life history traits. Bull. Ent. Res., 86, 407-417.

PARR, w. J. AND HUSSEY, N. w. 1960. Further studies on the reproductive isolation of geographical strains in the Tetranychus urticae complex. Entomologia exp. appl., 3, 137-141.

PÉREZ-SUAREZ, G., PAlacios, F. AND BOURSOT, P. 1994. Speciation and paraphyly in western Mediterranean hares (Lepus castroviejoi, L. europaeus, L. granatenis, and L. capensis) revealed by mitochondrial DNA phylogeny. Biochem. Genet., 32, 423-436.

PORTER, C. H. AND COLLINS, F. H. 1991. Species-diagnostic differences in a ribosomal DNA internal transcribed spacer from the sibling species Anopheles freeborni and Anopheles hermsi (Diptera: Culicidae). Am. J. Trop.
Med. Hyg., 45, 271-279.

SCHLÖTTERER, C., HAUSER, M.-T., VON HAESELER, A. AND TAUTZ, D. 1994. Comparative evolutionary analysis of rDNA ITS regions in Drosophila. Mol. Biol. Evol., 11, 513-522.

SIMON, C., FRATI, F., BECKENBACH, A., CRESPI, B., LIU, H. AND FLOOK, P. 1994. Evolution, weighting and phylogenetic utility of mitochondrial gene sequences and a compilation of conserved polymerase chain reaction primers. Ann. Entomol. Soc. Am., 87, 651-701.

SмITH, G. P. 1976. Evolution of repeated DNA sequences by unequal crossovers. Science, 191, 528-534.

TAMURA, K. 1992. Estimation of the number of nucleotide substitutions when there are strong transition-transversion and $\mathrm{G}+\mathrm{C}$ content biases. Mol. Biol. Evol., 9, 678-687.

TANG, J., TOÈ, L., BACK, C. AND UNNASCH, T. R. 1996. Intraspecific heterogeneity of the rDNA internal transcribed spacer in the Simulium damnosum (Diptera: Simuliidae) complex. Mol. Biol. Evol., 13, 244-252.

TSAGKARAKOU, A., GUillemaud, T., ROUSSET, F. AND NAVAJAS, M. 1996. Molecular identification of a Wolbachia endosymbiont in a Tetranychus urticae strain (Acari: Tetranychidae). Insect Mol. Biol., 5, 217-221.

TSAGKARAKOU, A., NAVAJAS, M., LAGNEL, J. AND PASTEUR, N. 1997. Population structure in the spider mite Tetranychus urticae (Acari:Tetranychidae) from Crete based on multiple allozymes. Heredity, 78, 84-92.

TSAGKARAKOU, A., NAVAJAS, M., P-SOUliotis, P. AND PASTEUR, N. 1998. Gene flow among Tetranychus urticae (Acari: Tetranychidae) populations in Greece. Mol. Ecol., 7, 71-79.

veERman, A. 1970. The pigments of Tetranychus cinnabarinus (Acari: Tetranychidae). Comp. Biochem. Physiol., 36, 749-763.

veERman, A. 1974. Carotenoid metabolism in Tetranychus urticae Koch (Acari: Tetranychidae). Comp. Biochem. Physiol., 47, 101-116.

VOGLER, A. P. AND DESALLE, R. 1994. Evolution and phylogenetic information content of the ITS-1 region in the tiger beetle Cicindela dorsalis. Mol. Biol. Evol., 11, 393-405.

WESSON, D. M., MCLAin, D. K., OLIVER, J. H., PIESMAN, J. AND COLLINS, F. H. 1993. Investigation of the validity of species status of Ixodes dammini (Acari: Ixodidae) using rDNA. Proc. Natl. Acad. Sci. U.S.A., 90, 10221-10225.

WESSON, D. M., PORTER, C. H. AND COLLINS, F. H. 1992. Sequence and secondary structure comparisons of ITS rDNA in mosquitoes (Diptera: Culicidae). Mol. Phylogenet. Evol., 1, 253-269. 